Biosimilars for Healthcare Professionals

For personal use only. Not to be reproduced without permission of the publisher (editorial@gabi-journal.net).

\section{Regulatory Science Ireland: bridging the information gap on biosimilar medicines}

\section{Joan O'Callaghan 1,2,3, BSc Pharm; Sean Barry', PhD; Una Moore', PhD; Margaret Bermingham ${ }^{2}$, PhD; J Michael Morris ${ }^{3}$, PhD; Frank Hallinan ${ }^{2,3}$, PhD; Brendan T Griffin ${ }^{2,3}, \mathrm{PhD}$}

Regulatory Science Ireland (RSI) is a voluntary network of interested parties from academia, the Health Products Regulatory Authority (HPRA), pharmaceutical and medical device industries and government agencies. RSI is conducting a research project, the objective of which is to enhance understanding of biosimilar medicines amongst stakeholders and encourage best practice in the use of these medicines.

Keywords: Biological medicines, biosimilar, Health Products Regulatory Authority, regulatory science, Regulatory Science Ireland

\section{Regulatory Science Ireland \\ The ever increasing complexity of healthcare products requires a data driven, evidence- based approach to their regulation. The European Medicines Agency (EMA) has identified regulatory science as a key driver to meet its mission of fostering 'scientific excel- lence in the evaluation and supervision of medicines' [1]. Regulatory science is becom- ing increasingly important as an approach to how medicines are developed and regulated. EMA recognizes this fact and recommends that regulators work closely with academia, industry, expert patient groups and others in order to support developments in this area [2].}

Regulatory Science Ireland (RSI) is an integrated Irish response to global regulatory science initiatives. The group is composed of interested parties from the Health Products Regulatory Authority (HPRA), academia, pharmaceutical industry, medical devices industry and government agencies, see Figure 1 . RSI is contributing to the regulatory science effort by conducting research, provision of educational materials and organization of regulatory symposia. Efforts such as these will help improve regulatory understanding among all stakeholders and will ultimately be of real benefit to patients.

Why is RSI focusing on biological and biosimilar medicines?

A biological medicine is a medicine that contains an active substance made by a biological process or derived from a biological source. The standards for the quality, safety and efficacy of biological medicines are complex and it is essential that healthcare professionals involved in their clinical use and supply are appropriately informed of their unique characteristics. Biosimilar medicines are biological medicines which contain a version of the active substance of an already authorized biological medicine
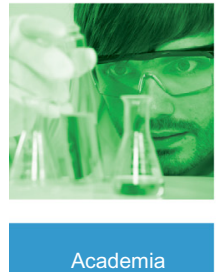

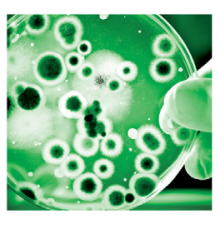

Regulatory body (reference medicine). Manufacturers of biosimilar medicines must perform an extensive head-to-head comparability exercise with the reference medicine and demonstrate to regulators that the biosimilar medicine has similar quality, safety and efficacy to the reference medicine such that there are no clinically meaningful differences between the two.

The biosimilar approval process is based predominantly on evidence generated from the quality and preclinical comparability exercise. The extent of clinical data needed to demonstrate similarity in addition to the quality and non-clinical data is tailored to each product on a case-by-case basis and is considered confirmatory in nature. Therefore depending on the nature of the product, the clinical data can range from limited to extensive. Reliance on quality evidence over clinical evidence may be an unusual concept for those that know a biosimilar medicine is 'similar but not identical' to the reference medicine. The biosimilar medicine may also be licensed in therapeutic indications for which no specific clinical trials have been conducted. This is commonly referred to as indication extrapolation and is only approved by regulators after comprehensive scientific justification which includes consideration of the mechanism of action in each indication.

\section{Figure 1: Regulatory Science Ireland membership}

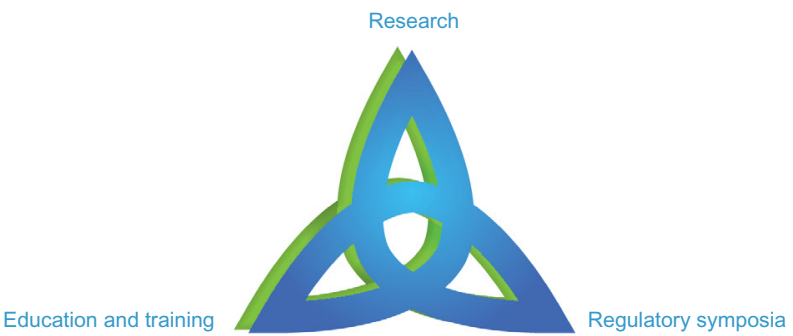

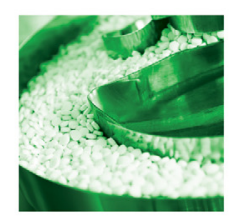

Pharmaceutical

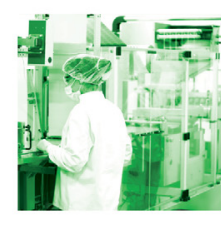

Medical devices

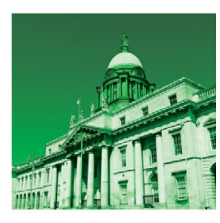

Government Government

Author for correspondence: Joan O'Callaghan, BSc Pharm, Research Scientist, Regulatory Science Ireland, Health Products Regulatory Authority, Kevin O'Malley House, Earlsfort Centre, Earlsfort Terrace, Dublin 2, Ireland

Submitted: 26 October 2016; Revised: 26 October 2016; Accepted: 27 October 2016; Published online first: 31 October 2016 
A key output from the RSI biosimilar project is to identify and implement mechanisms to increase the understanding of how these medicines are regulated and used amongst healthcare professionals, patients and healthcare providers.

\section{HPRA guide to biosimilar medicines}

Prior to commencement of the RSI biosimilar project, the HPRA was already engaged in activities to facilitate knowledge transfer concerning biosimilar medicines to stakeholders. In 2015, the HPRA published a guide to biosimilar medicines [3]. This guide is targeted primarily at healthcare professionals but is also relevant to patients, manufacturers, distributors and those involved in hospital procurement. Some of the drivers for producing the guide are outlined in Table 1.

The guide provides an overview of how biosimilar medicines are regulated and outlines the difference between a biosimilar medicine and a generic (chemical) medicine. Topics such as pharmacovigilance considerations, adverse drug reaction reporting, prescribing, and interchangeability are also addressed. A public consultation process was undertaken before finalization of the guide which allowed the HPRA to gather feedback from stakeholders as to whether it provided enough relevant information to meet their needs. Comments from stakeholders were considered and incorporated as appropriate. While the publication of such guidance documents can help in addressing some of the misconceptions surrounding biosimilar medicines, the HPRA is continuing in its efforts to bridge the information gap on biosimilar medicines by providing dedicated resources to the RSI Biosimilar Research Project.

\section{RSI Biosimilar Research Project}

Biosimilar medicines were highlighted as being a key area of interest for the development of the regulatory science knowledge base in Ireland and therefore a biosimilar research project was launched as one of the first major projects for RSI. The project, which has been ongoing since January 2016, involves a collaboration between the HPRA and University College Cork (UCC). The research is also supported by the Irish Pharmaceutical Healthcare Association (IPHA). A project advisory panel meet quarterly to share ideas about the direction of the research. In addition to HPRA and UCC, the advisory panel consists of stakeholders from industry, industry representative bodies, a patient representative and government agencies.

The project focuses on a number of specific objectives relating to enhanced pharmacovigilance and traceability of biological medicines and the need for procurement/ purchasing procedures to appreciate the difference between biosimilar medicines and generic medicines.

The project objectives include:

- Peer-reviewed scientific publications on biosimilar medicines - particularly concerning the practical considerations for healthcare professionals

- Conducting surveys of healthcare professionals on perspectives and understandings of issues relating to biosimilar medicines

- Development of training materials and online resources

- Participation in outreach activities, e.g. running short training courses, information days, invited lectures

Research activities are conducted independently by the HPRA and UCC which ensures the generation of unbiased neutral information relating to the use of biosimilar medicines by healthcare professionals.

\section{Survey of physicians}

An early goal of the project is to evaluate the level of understanding about biosimilar medicines amongst Irish healthcare professionals. In May 2016, a link to an online questionnaire was circulated to medical specialists (preTable 1: Reasons for producing HPRA guide on biosimilar medicines

- Perceived uncertainty among healthcare professionals

- Lack of understanding of the biosimilar approval process

- Misconceptions around indication extrapolation

- Perceived lack of awareness amongst healthcare professionals (and patients) of the differences between a biosimilar and a generic medicine

- Possible dependence among healthcare professionals on anecdotal information about biosimilars

HPRA: Health Products Regulatory Authority to biological and biosimilar medicines. The questionnaire addressed topics such as familiarity with the term 'biosimilar', implications of shared international nonproprietary names, pharmacovigilance recording practices, prescribing behaviours, attitudes to pharmacist led substitution and specific concerns relating to biosimilar medicines. The results from the survey are currently being analysed and will shortly be submitted for publication.

\section{Stakeholder engagement}

Many medical specialists in Ireland are members of professional societies. Societies, whose members are likely to be involved in the prescribing of biological medicines, have facilitated the research by distribution of the online questionnaire to their members. Continued engagement with the societies is envisaged after publication of the survey findings.

Engagement with GPs has been facilitated by the Irish College of General Practitioners (ICGP). The ICGP is the professional body for general practice in Ireland and its members and associates account for over $85 \%$ of practising GPs. The College agreed to distribute the questionnaire to its membership and organized a speaking slot for RSI at an educational conference organized for their members.

Pharmacists have been kept informed of key aspects of biosimilar regulation and their use in clinical practice via RSI presentations at continuing education events and publication of papers in national pharmacy journals (Irish Pharmacy News and the Hospital Pharmacist News). An article highlighting the importance of traceability of biological medicines has been published on the RSI website [4]. Pharmacists were informed of this material via a newsletter distributed by the Pharmaceutical Society of Ireland.

The RSI project team also aims to facilitate knowledge transfer to patient communities. Representatives from various patient organizations have been made aware of the project at a recent event on 'Biologicals and Biosimilars' organized by the Irish Platform for Patients' Organisations, Science \& Industry (IPPOSI). IPPOSI has also conducted a recent survey of 150 arthritis patients [5]. The findings suggest that awareness and understanding of biosimilars amongst patients is low. Respondents also felt that there was limited access to patient friendly, easily understandable 


\section{Biosimilars for Healthcare Professionals}

information about biological and biosimilar medicines. This identified need has resulted in the RSI publication of a patient Q \& A which can be found on the RSI website [6]. It is planned to produce a short informative video to accompany the $\mathrm{Q} \& \mathrm{~A}$. Once finalized the materials will be publicized to relevant patient organizations.

\section{Ongoing activities}

Materials generated from the project will be available for download from the RSI website (www.regulatoryscienceireland.ie). Research findings will be disseminated to healthcare professionals, patients, payers and policymakers. Outreach activities will continue as the project gains momentum and it is planned to organize and contribute to future events involving key stakeholders.

\section{Conclusion}

Since its inception, RSI has made significant progress in increasing the awareness and understanding of the regulation, prescription and use of biosimilar medicines in Ireland. However, a level of misunderstanding around the whole area still persists. Through our future research, outreach programmes and engagement activities, RSI plans to bridge the knowledge gap between industry, regulators, healthcare professionals and patients, and contribute to the safe and effective use of biological medicines in Ireland.

\section{Acknowledgements}

Regulatory Science Ireland acknowledge the financial support provided by the Irish Pharmaceutical Healthcare Association and the Health Products Regulatory Authority for the conduct of this research.

\section{Competing interests: None.}

Provenance and peer review: Commissioned; internally peer reviewed.

\section{Authors}

Joan O'Callaghan ${ }^{1,2,3}$, BSc Pharm

Sean Barry ${ }^{1}$, PhD

Una Moore ${ }^{1}$, PhD

Margaret Bermingham ${ }^{2}, \mathrm{PhD}$

J Michael Morris ${ }^{3}, \mathrm{PhD}$

Frank Hallinan ${ }^{2,3}, \mathrm{PhD}$

Brendan T Griffin ${ }^{2,3}$, PhD

${ }^{1}$ Health Products Regulatory Authority, Kevin O'Malley House, Earlsfort Centre, Earlsfort Terrace, Dublin 2, Ireland

${ }^{2}$ School of Pharmacy, Cavanagh Pharmacy Building, University College Cork, Cork, Ireland

${ }^{3}$ Regulatory Science Ireland, c/o School of Pharmacy, Cavanagh Pharmacy Building, University College Cork, Cork, Ireland

\section{References}

1. European Medicines Agency. Road map to 2015 [homepage on the Internet]. 2010 [cited 2016 Oct 26]. Available from: http://www.ema.europa.eu/docs/en_ GB/document_library/Report/2011/01/WC500101373. pdf

2. European Medicines Agency. EU Medicines Agencies Network Strategy to 2020 [homepage on the Internet]. 2015 [cited 2016 Oct 26]. Available from: http:// www.ema.europa.eu/docs/en_GB/document_ library/Other/2015/12/WC500199060.pdf

3. Health Products Regulatory Authority. Guide to biosimilars for healthcare professionals and patients [homepage on the Internet]. 2015 [cited 2016 Oct 26]. Available from: https://www.hpra.ie/docs/defaultsource/publications-forms/guidance-documents/ guide-to-biosimilars-for-healthcare-professionalsand-patients-v2.pdf?sfvrsn $=18$

4. Regulatory Science Ireland. Pharmacovigilance considerations for biological medicines [homepage on the Internet]. 2016 [cited 2016 Oct 26]. Available from: http://www.regulatoryscienceireland.com/ pharmacovigilance-of-biological.html

5. IPPOSI. IPPOSI patient survey [homepage on the Internet]. 2016 [cited 2016 Oct 26]. Available from: http://www.ipposi.ie/images/Appendix_I_-graphs_from_survey_v5.pdf

6. Regulatory Science Ireland. Biosimilar medicines: what patients should know [homepage on the Internet]. 2016 [cited 2016 Oct 26]. Available from: http://

www.regulatoryscienceireland.com/biosimilars.html DOI: $10.5639 /$ gabij.2016.0504.043

Copyright (C 2016 Pro Pharma Communications International 